\title{
Women's Physical Health, Mental Health, and Practical Hints for Common Practice Issues
}

\section{Research from Community Health Centers}

In this March-April 2009 issue, we have articles from 2 different community health center (CHC) groups. ${ }^{1,2} \mathrm{CHCs}$ provide much care, particularly for the uninsured in the United States. ${ }^{3}$ As such, research in these offices is of value because they reflect real-life practice and an important group of practices in the United States; we would like to encourage more such research. Hicks et $\mathrm{al}^{1} \mathrm{dem}-$ onstrate that, with minimal instructions, $\mathrm{CHC}$ patient self-collection seems to function as well as physician collection of group $\beta$ streptococcal specimens during patients' pregnancies. Using patient self-collection would save physician time. In the second CHC study, Ani et $\mathrm{al}^{2}$ report that the rate of diagnosis in depression patients seemed unchanged by concurrent chronic medical illnesses. In an editorial reflection on the Ani et $\mathrm{al}^{2}$ paper, Bowman ${ }^{4}$ has provided a provocative perspective about the "competing demands" theory: moving away from focusing on competing demands within the specific patient and visit, as commonly occurs, and instead spreading demands over time and across patients allows family physicians to be TOPS at prioritizing the most important issues in their practices.

\section{Obesity}

Obesity remains a topic of major interest. According to Phelan et al, ${ }^{5}$ family physicians make recommendations to obese patients that are both consistent and not consistent with the evidence-based literature. In particular, physicians did not suggest recording weights or food intake, decreasing television viewing, or using meal replacements or medications, all of which are supported as good weightloss techniques. Be sure to read the associated commentary by Greenwood. ${ }^{6}$

\section{Pregnancy and Family Planning}

Fertility awareness-based methods for family planning (either to prevent or achieve pregnancy) are

Conflict of interest: The authors are editors of the $7 A B F M$. underused and relatively unknown. ${ }^{7}$ When given information, more women would like to pursue these methods. There are several methods that go beyond the commonly known basal body temperature and rhythm methods, which are not particularly effective. Some methods permit intermittent use of barrier methods. Few physicians have received much education about these, and very few include it as an option when discussing pregnancy prevention. Pallone et $\mathrm{al}^{7}$ provide data showing that the "standard day" and "2-day" methods can be taught during 1 office visit.

Have you thought about sleep apnea during pregnancy? It does occur, and the Venkata and Venkateshiah $^{8}$ article helps to sort out what is known. More data about outcomes of sleep apnea during pregnancy would be important, but if one merely extracts from what is known for non-pregnancy-associated sleep apnea, adverse consequences for the fetus would be expected. This is a new area for further research. Lyus et $\mathrm{al}^{9}$ document that first trimester procedural abortions are safe in family medicine offices, which is similar to recent data abotu medical abortions. ${ }^{10}$

\section{Anxiety and Mental Health}

Several articles in this issue focus on mental health. A reflection on Alzheimer disease by Arora ${ }^{11}$ reminds us of the humanity of all patients. A practical, evidenced-based approach for treating the 4 most common anxiety disorders is presented by Roy-Byrne et al, ${ }^{12}$ including short questionnaires and general therapeutic counseling techniques. A combination of focused therapy and medications can be quite useful. You can download these tools to use in your practice through the online fournal.

For those people with serious mental illnesses, the family physician's role is more likely to be managing their concurrent medical illnesses. Morden et $\mathrm{al}^{13}$ suggest that "serious mental illness should be considered a cardiovascular disease risk equivalent"; these patients are most likely to die of cardiovascular disease and do so at a substantially higher rate than the general public. Thus, much of 
our effort should be toward decreasing all modifiable cardiovascular risks when we see patients with serious mental illnesses.

Continuing the mental health theme with a cardiovascular subtext, Jiao et $\mathrm{al}^{14}$ provides a case report of a non-q-wave myocardial infarction occurring in a young man who drank alcohol then restarted his Adderall XR, taking 30 mg, after missing multiple doses. This is concerning, and hopefully there will not be more case reports of this nature. It has reminded me (MAB) to tell patients not to miss doses and then restart at higher doses, which I know some have done.

\section{Colorectal Cancer Screening}

Nemeth et $\mathrm{al}^{15}$ use a case study approach to describe high performance for colorectal cancer screening, explain practice strategies, and provide a quality improvement model for improving colorectal cancer screening in primary care. They demonstrate an approach that involved all staff to prioritize practice performance, and used emergency medical record tools to facilitate system redesign that can result in patient activation.

\section{Clinical Case Reports from Primary Care}

Patent ductus arteriosis can be discovered in adults, often relatively incidentally. Cassidy et $\mathrm{al}^{16}$ review the increasing incidence, presentation, work-up, and treatment. Surgery is still often used to close asymptomatic patent ductus arteriosis to prevent further complications, such as bacterial endocarditis or heart failure.

In another case report, Reamy ${ }^{17}$ presents a patient with postepidural headache occurring 12 days after the epidural (longer than usually expected), and a helpful reminder for those seeing postpartum patients. Excellent photographs of discoid lupus of the scalp are included in Panjwani's ${ }^{18}$ review of the treatment of this entity, which also includes some thoughts on using some of the newer medications beyond the typical topical steroids, sunscreens, and antimalarials.

Often the first thought with new-onset Horner syndrome would not be Lyme disease, but that is what is presented in a case report by Morrison et al. ${ }^{19}$ Once again, we see that Lyme disease can be a great imitator and cause a great variety of clinical manifestations, including Horner syndrome.
With excellent observational work from practice, clinical reviews, and case reports from the field, the $7 A B F M$ researchers and authors continue to bring us improved information for practice.

Marjorie A. Bowman, MD, MPA

Anne Victoria Neale, PhD, MPH

\section{References}

1. Hicks P, Diaz-Perez MJ. Patient self-collection of group B streptococcal specimens during pregnancy. J Am Board Fam Med 2009;22:136-40.

2. Ani C, Bazargan M, Hindman D, Bell D, Rodriguez M, Baker R. Comorbid chronic illness and the diagnosis and treatment of depression in safety net primary care settings. J Am Board Fam Med 2009;22: 23-35.

3. National Association of Community Health Centers, The Robert Graham Center, Capital Link. Access granted: The primary care payoff. August 2007. Available at: http://www.graham-center.org/online/ etc/medialib/graham/documents/publications/mon graphs-books/2007/rgcmo-access-granted.Par.0001. File.tmp/rgcmo-access-granted.pdf. Accessed 22 January 2008.

4. Bowman MA. TOP docs: family physicians with competing demands and the right priorities-individual, family and community health. J Am Board Fam Med 2009;22:110-2.

5. Phelan S, Nallari M, Darroch FE, Wing RR. What do physicians recommend to their overweight and obese patients? J Am Board Fam Med 2009;22:11522.

6. Greenwood JLJ. The complexity of weight loss counseling. J Am Board Fam Med 2009;22:113-4.

7. Pallone SR, Bergus GR. Fertility awareness-based methods: another option for family planning. J Am Board Fam Med 2009;22:147-57.

8. Venkata C, Venkateshiah SB. Sleep disordered breathing during pregnancy. J Am Board Fam Med 2009;22:158-68.

9. Lyus RJ, Guiantsos P, Gold M. First trimester procedural abortion in family medicine. J Am Board Fam Med 2009;22:169-74.

10. Prine L, Lesnewski R, Berley N, Gold M. Medical abortion in family practice: a case series. J Am Board Fam Pract 2003;16:290-5.

11. Arora V. Lost: reflection on Alzheimer disease. J Am Board Fam Med 2009;22:196.

12. Roy-Byrne P, Veitengruber JP, Bystritsky A, et al. Brief intervention for anxiety in primary care patients. J Am Board Fam Med 2009;22:175-86.

13. Morden NE, Mistler LA, Weeks WB, Bartels SJ. Health care for patients with serious mental illness: family medicine's role. J Am Board Fam Med 2009;22:187-95.

14. Jiao X, Velez S, Ringstad J, Eyma V, Miller D, 
Bleiberg M. Myocardial infarction associated with Adderall XR and alcohol use in a young man. J Am Board Fam Med 2009;22:197-201.

15. Nemeth LS, Nietert PJ, Ornstein SM. High performance in screening for colorectal cancer: a Practice Partner Research Network (PPRNet) case study. J Am Board Fam Med 2009;22:141-6.

16. Cassidy HD, Cassidy LA, Blackshear JL. Incidental discovery of a patent ductus arteriosis in adults. J Am Board Fam Med 2009;22:214-8.
17. Reamy BV. Post-epidural headache: how late can it occur? J Am Board Fam Med 2009;22(2):202-5.

18. Panjwani, S. Early diagnosis and treatment of discoid lupus erythematosus. J Am Board Fam Med 2009; 22:206-13

19. Morrison C, Seifter A, Aucott JN. Unusual presentation of Lyme disease: Horner syndrome with negative serology. J Am Board Fam Med 2009;22:219_ 22. 